Original Article

\title{
INFLUENCE OF FORMULATION FACTORS ON THE SIZE OF NANOSTRUCTURED LIPID CARRIERS AND NANOEMULSIONS PREPARED BY HIGH SHEAR HOMOGENIZATION
}

\author{
AHMED R. GARDOUH ${ }^{*}$, SAMAR H. FAHEIM ${ }^{2}$, AHMED T. NOUH ${ }^{3}$, MAMDOUH M. GHORAB ${ }^{1}$
}

${ }^{1}$ Department of Pharmaceutics and Industrial Pharmacy, Faculty of Pharmacy, Suez Canal University, Ismailia, Egypt, ${ }^{2}$ Department of Pharmaceutics, Faculty of Pharmacy, Horus University, New Damietta, Egypt, ${ }^{2}$ Department of Pharmaceutics, Faculty of Pharmacy, Delta University, Gamasa, Mansoura, Egypt

Email: Ahmed_mahmoud@pharm.suez.edu.eg

Received: 15 Oct 2017 Revised and Accepted: 08 Mar 2018

\begin{abstract}
Objective: The main purpose of this work was to elucidate the effect of certain formulation factors on the size of nanostructured lipid carriers (NLCs) and nanoemulsions (NEs) by using high shear homogenization method.

Methods: NLCs and NEs were prepared by high shear homogenization method using different liquid lipids types such as (Dermarol DCO® and Dermarol CCT $®$ ) at different concentrations. The effect of different concentration ratios of Tween 80 to Span $20(2.5 / 1,5 / 1,10 / 1,15 / 1)$ w/w \% and different homogenization speeds $(12000,18000 \mathrm{rpm})$ on the resulted particle size were also studied.
\end{abstract}

Results: The results revealed that the optimum NLCs and NEs resulted when we use Dermarol CCT® with a concentration of $90 \%$ as liquid lipid and decreasing surfactant ratio to $(2.5 / 1) \mathrm{w} / \mathrm{w} \%$ with increasing the homogenization speed to $18000 \mathrm{rpm}$.

Conclusion: NLCs and NEs were successfully prepared, and from this study, it can be concluded that NLCs have the optimum particle size than Nanoemulsions.

Keywords: Nanostructured lipid carriers, Nanoemulsions, Surfactants, Liquid lipids, High Shear Homogenizer

(C) 2018 The Authors. Published by Innovare Academic Sciences Pvt Ltd. This is an open access article under the CC BY license (http://creativecommons.org/licenses/by/4.0/) DOI: http://dx.doi.org/10.22159/ijpps.2018v10i4.23142

\section{INTRODUCTION}

In recent years, it has got to be clear that the advancement of novel medications is deficient for ensuring the advancement in medical treatment. The data obtained in the in vitro studies are often trailed by disappointing results in the in vivo or clinical circumstance. Predominant reasons for this failure are the insufficient drug level In the body due to its rapid metabolism, the high medication poisonous quality in view of broad distribution, and a high fluctuation of plasma medication levels [1].

A few methodologies have recently been explored to create nanosized drug delivery systems. These systems can be partitioned into two gatherings: polymeric and lipid systems [2]. The quantity of items in view of polymeric nanoparticles in the business sector is restricted in light of the poisonous quality of polymers, what's more, the absence of suitable expansive scale generation strategies. All together to conquer these issues, a lot of hope has been centred on lipid-based carriers, for example, nanoemulsions (NEs) and nanostructured lipid carriers (NLCs). NEs are medication conveyance systems comprising of emulsified oil and water systems with mean droplet diameters ranging from 50 to $1000 \mathrm{~nm}$. Generally, the normal droplet size is somewhere around 100 and $500 \mathrm{~nm}$ and can exist as oil-in-water (o/w) or waterin-oil (w/o) form, where the internal phase is either oil or water, separately $[3,4]$. These systems have points of interest for medication conveyance, for example, the utilization of physiologically tolerated lipids, large-scale production, prevent the medications from destruction, enhanced bioavailability, and controlled-release qualities [5]. The flaws of NEs are poor drug loading capacities, medication deterioration during storage and they have physical instability that can be increased by the joined drug $[6,7]$. NLCs made out of a strong lipid matrix with a certain content of a fluid lipid are another era of lipid nanoparticles. NLCs are viewed as a more advanced era of nanoparticles, which have enhanced properties for drug loading, adjustment of the delivery profile, and stable medication during storage [8-11]. Because of the lipophilic content of the NLCs, they are considered especially helpful in the administration of lipophilic medications.
Broadly speaking, energy is normally required in emulsion formulation in light of the fact that the procedure may be nonspontaneous. The creation of nanoemulsions expenses more energy than that required to deliver macroemulsions [12].

High-energy emulsification routines make utilization of instruments that use high mechanical energy to make nanoemulsions with high kinetic energy. The mechanical instruments make serious disruptive forces which separate the oil and water stages to make Nano-sized droplets. This can be accomplished with ultrasonicators, micro fluidizer and high shear Homogenizers [13-15]. Molecule size here will rely on the type of instruments utilized and their working conditions like time and temperature alongside sample properties and compositions [16].

The objective of the present work was to study the effect of certain formulation factors on the size of NLCs and NEs in order to realize the optimum formulation factors that give the optimum particle size.

\section{MATERIALS AND METHODS}

\section{Materials}

Naterol GMS $®$ (Glyceryl stearate) as solid lipid, Dermarol DCO® is an ester of decyl alcohol and oleic acid (Decyl Oleate), Dermarol CCT $\AA ~ \AA$ is a mixed triester of glycerin and Caprylic and Capric acids (Caprylic/Capric triglyceride) as liquid lipids and Tween 80® (Polysorbate80) as-surfactant were obtained from CISME Italy s. n. c. via Marcora, Milano-Italy. Span 20® (Sorbitan monolaurate) assurfactant, and Lecithin $®$ (cosurfactant). All other chemicals are of HPLC grade.

\section{Preparation of NLCs and NEs}

NLCs and NEs were prepared by high shear hot homogenization method $[17,18]$. Briefly, the lipid phase consisted of Naterol GMS, as solid lipid in case of NLC was melted at $80^{\circ} \mathrm{C}$ and then mixed with the liquid lipid Dermarol DCO ${ }^{\circledR}$ or Dermarol CCT $®$ and added to the Oily surfactants (Span 20 and Lecithin), or the liquid lipids Dermarol 
DCO $₫$ or CCT $®$ Dermarol CCT $®$ in case of NE was added to the Oily surfactants (Span 20 and Lecithin). An aqueous surfactant phase consists of Tween 80 was heated up to the same temperature of the molten lipid phase. The hot surfactant solution was poured onto the hot lipid phase and homogenization was carried out at 12,000 or 18 , $000 \mathrm{rpm}$ for 4 cycles (2 min with $30 \mathrm{~s}$ off) using high shear homogenizer (IKA T25 digital Ultra-Turrax Germany), Then leave to cool to room temperature.

Table 1: NLC prepared at 12000 and $18000 \mathrm{rpm}$ using liquid lipid dermarol DCO® and different surfactant ratio

\begin{tabular}{|c|c|c|c|c|}
\hline $\begin{array}{l}\text { NLC formula code prepared at } 12000 \\
\text { rpm }\end{array}$ & $\begin{array}{l}\text { NLC formula code prepared at } 18000 \\
\text { rpm }\end{array}$ & $\begin{array}{l}\text { Naterol GMS } \\
(\mathrm{w} / \mathrm{w} \%)\end{array}$ & $\begin{array}{l}\text { Dermarol DCO® } \\
(\mathbf{w} / \mathbf{w} \%)\end{array}$ & Tween/Span \\
\hline NLC1 & NLC1 ${ }^{*}$ & $90 \%$ & $10 \%$ & $2.5 / 1$ \\
\hline NLC2 & NLC2* & $80 \%$ & $20 \%$ & \\
\hline NLC3 & NLC3* & $70 \%$ & $30 \%$ & \\
\hline NLC4 & NLC4* & $60 \%$ & $40 \%$ & \\
\hline NLC5 & NLC5* & $50 \%$ & $50 \%$ & \\
\hline NLC6 & NLC6* & $40 \%$ & $60 \%$ & \\
\hline NLC7 & NLC7* & $30 \%$ & $70 \%$ & \\
\hline NLC8 & NLC8* & $20 \%$ & $80 \%$ & \\
\hline NLC9 & NLC9* & $10 \%$ & $90 \%$ & \\
\hline NLC1 & NLC1* & $90 \%$ & $10 \%$ & $5 / 1$ \\
\hline NLC2 & NLC2* & $80 \%$ & $20 \%$ & \\
\hline NLC3 & NLC3* & $70 \%$ & $30 \%$ & \\
\hline NLC4 & NLC4* & $60 \%$ & $40 \%$ & \\
\hline NLC5 & NLC5* & $50 \%$ & $50 \%$ & \\
\hline NLC6 & NLC6* & $40 \%$ & $60 \%$ & \\
\hline NLC7 & NLC7* & $30 \%$ & $70 \%$ & \\
\hline NLC8 & NLC8* & $20 \%$ & $80 \%$ & \\
\hline NLC9 & NLC9* & $10 \%$ & $90 \%$ & \\
\hline NLC1 & NLC1* & $90 \%$ & $10 \%$ & $10 / 1$ \\
\hline NLC2 & NLC2* & $80 \%$ & $20 \%$ & \\
\hline NLC3 & NLC3* & $70 \%$ & $30 \%$ & \\
\hline NLC4 & NLC4* & $60 \%$ & $40 \%$ & \\
\hline NLC5 & NLC5* & $50 \%$ & $50 \%$ & \\
\hline NLC6 & NLC6* & $40 \%$ & $60 \%$ & \\
\hline NLC7 & NLC7* & $30 \%$ & $70 \%$ & \\
\hline NLC8 & NLC8* & $20 \%$ & $80 \%$ & \\
\hline NLC9 & NLC9* & $10 \%$ & $90 \%$ & \\
\hline NLC1 & NLC1* & $90 \%$ & $10 \%$ & $15 / 1$ \\
\hline NLC2 & NLC2* & $80 \%$ & $20 \%$ & \\
\hline NLC3 & NLC3* & $70 \%$ & $30 \%$ & \\
\hline NLC4 & NLC4* & $60 \%$ & $40 \%$ & \\
\hline NLC5 & NLC5* & $50 \%$ & $50 \%$ & \\
\hline NLC6 & NLC6* & $40 \%$ & $60 \%$ & \\
\hline NLC7 & NLC7* & $30 \%$ & $70 \%$ & \\
\hline NLC8 & NLC8* & $20 \%$ & $80 \%$ & \\
\hline NLC9 & NLC9* & $10 \%$ & $90 \%$ & \\
\hline
\end{tabular}

Table 2: NLC formulae prepared at 12000 and $18000 \mathrm{rpm}$ using liquid lipid Dermarol CCT® and different surfactant ratio

\begin{tabular}{|c|c|c|c|c|}
\hline $\begin{array}{l}\text { NLC Formula code } \\
\text { prepared at } 12000 \mathrm{rpm}\end{array}$ & NLC Formula code prepared at $18000 \mathrm{rpm}$ & $\begin{array}{l}\text { Naterol GMS } \\
(w / w \%)\end{array}$ & $\begin{array}{l}\text { Dermarol CCT } ® \\
(w / w \%)\end{array}$ & Tween/Span \\
\hline NLC10 & NLC10* & $90 \%$ & $10 \%$ & $2.5 / 1$ \\
\hline NLC11 & NLC11* & $80 \%$ & $20 \%$ & \\
\hline NLC12 & NLC12* & $70 \%$ & $30 \%$ & \\
\hline NLC13 & NLC13* & $60 \%$ & $40 \%$ & \\
\hline NLC14 & NLC14* & $50 \%$ & $50 \%$ & \\
\hline NLC15 & NLC15* & $40 \%$ & $60 \%$ & \\
\hline NLC16 & NLC16* & $30 \%$ & $70 \%$ & \\
\hline NLC17 & NLC17* & $20 \%$ & $80 \%$ & \\
\hline NLC18 & NLC18* & $10 \%$ & $90 \%$ & \\
\hline NLC10 & NLC10* & $90 \%$ & $10 \%$ & $5 / 1$ \\
\hline NLC11 & NLC11* & $80 \%$ & $20 \%$ & \\
\hline NLC12 & NLC12* & $70 \%$ & $30 \%$ & \\
\hline NLC13 & NLC13* & $60 \%$ & $40 \%$ & \\
\hline NLC14 & NLC14* & $50 \%$ & $50 \%$ & \\
\hline NLC15 & NLC15* & $40 \%$ & $60 \%$ & \\
\hline NLC16 & NLC16* & $30 \%$ & $70 \%$ & \\
\hline NLC17 & NLC17* & $20 \%$ & $80 \%$ & \\
\hline NLC18 & NLC18* & $10 \%$ & $90 \%$ & \\
\hline NLC10 & NLC10* & $90 \%$ & $10 \%$ & $10 / 1$ \\
\hline NLC11 & NLC11* & $80 \%$ & $20 \%$ & \\
\hline NLC12 & NLC12* & $70 \%$ & $30 \%$ & \\
\hline NLC13 & NLC13* & $60 \%$ & $40 \%$ & \\
\hline
\end{tabular}




\begin{tabular}{|c|c|c|c|c|}
\hline NLC14 & NLC14* & $50 \%$ & $50 \%$ & \\
\hline NLC15 & NLC15* & $40 \%$ & $60 \%$ & \\
\hline NLC16 & NLC16* & $30 \%$ & $70 \%$ & \\
\hline NLC17 & NLC17* & $20 \%$ & $80 \%$ & \\
\hline NLC18 & NLC18* & $10 \%$ & $90 \%$ & \\
\hline NLC10 & NLC10* & $90 \%$ & $10 \%$ & $15 / 1$ \\
\hline NLC11 & NLC11* & $80 \%$ & $20 \%$ & \\
\hline NLC12 & NLC12* & $70 \%$ & $30 \%$ & \\
\hline NLC13 & NLC13* & $60 \%$ & $40 \%$ & \\
\hline NLC14 & NLC14* & $50 \%$ & $50 \%$ & \\
\hline NLC15 & NLC15* & $40 \%$ & $60 \%$ & \\
\hline NLC16 & NLC16* & $30 \%$ & $70 \%$ & \\
\hline NLC17 & NLC17* & $20 \%$ & $80 \%$ & \\
\hline NLC18 & NLC18* & $10 \%$ & $90 \%$ & \\
\hline
\end{tabular}

Table3: NE formulae prepared at 12000 and 18000 rpm using different concentrations of liquid lipids Dermarol DCO®, Dermarol CCT and different surfactant ratio

\begin{tabular}{|c|c|c|c|c|}
\hline $\begin{array}{l}\text { NE Formula code } \\
\text { prepared at } 12000 \mathrm{rpm}\end{array}$ & $\begin{array}{l}\text { NE Formula code prepared at } \\
18000 \mathrm{rpm}\end{array}$ & $\begin{array}{l}\text { Dermarol DCO® } \\
(w / w \%)\end{array}$ & $\begin{array}{l}\text { Dermarol CCT } \AA \\
(w / w \%)\end{array}$ & Tween/Span \\
\hline NE1 & NE1* & $90 \%$ & $10 \%$ & $2.5 / 1$ \\
\hline NE2 & NE $2 *$ & $80 \%$ & $20 \%$ & \\
\hline NE3 & NE3* & $70 \%$ & $30 \%$ & \\
\hline NE4 & NE4* & $60 \%$ & $40 \%$ & \\
\hline NE5 & NE5* & $50 \%$ & $50 \%$ & \\
\hline NE6 & NE6* & $40 \%$ & $60 \%$ & \\
\hline NE7 & NE7* & $30 \%$ & $70 \%$ & \\
\hline NE8 & NE8* & $20 \%$ & $80 \%$ & \\
\hline NE9 & NE9* & $10 \%$ & $90 \%$ & \\
\hline NE1 & NE1* & $90 \%$ & $10 \%$ & $5 / 1$ \\
\hline NE2 & NE2* & $80 \%$ & $20 \%$ & \\
\hline NE3 & NE3* & $70 \%$ & $30 \%$ & \\
\hline NE4 & NE4* & $60 \%$ & $40 \%$ & \\
\hline NE5 & NE5* & $50 \%$ & $50 \%$ & \\
\hline NE6 & NE6* & $40 \%$ & $60 \%$ & \\
\hline NE7 & NE7* & $30 \%$ & $70 \%$ & \\
\hline NE8 & NE8* & $20 \%$ & $80 \%$ & \\
\hline NE9 & NE9* & $10 \%$ & $90 \%$ & \\
\hline NE1 & NE1* & $90 \%$ & $10 \%$ & $10 / 1$ \\
\hline NE2 & NE2* & $80 \%$ & $20 \%$ & \\
\hline NE3 & NE3* & $70 \%$ & $30 \%$ & \\
\hline NE4 & NE4* & $60 \%$ & $40 \%$ & \\
\hline NE5 & NE5* & $50 \%$ & $50 \%$ & \\
\hline NE6 & NE6* & $40 \%$ & $60 \%$ & \\
\hline NE7 & NE7* & $30 \%$ & $70 \%$ & \\
\hline NE8 & NE8* & $20 \%$ & $80 \%$ & \\
\hline NE9 & NE9* & $10 \%$ & $90 \%$ & \\
\hline NE1 & NE1* & $90 \%$ & $10 \%$ & $15 / 1$ \\
\hline NE2 & NE2* & $80 \%$ & $20 \%$ & \\
\hline NE3 & NE3* & $70 \%$ & $30 \%$ & \\
\hline NE4 & NE4* & $60 \%$ & $40 \%$ & \\
\hline NE5 & NE5* & $50 \%$ & $50 \%$ & \\
\hline NE6 & NE6* & $40 \%$ & $60 \%$ & \\
\hline NE7 & NE7* & $30 \%$ & $70 \%$ & \\
\hline NE8 & NE8* & $20 \%$ & $80 \%$ & \\
\hline NE9 & NE9* & $10 \%$ & $90 \%$ & \\
\hline
\end{tabular}

\section{Particle size analysis}

Particle size analysis of NLC and NE were carried out using Laser diffraction particle size analyzer (LD, Master size Malvern Instruments Ltd. Worcestershire. UK) at $25^{\circ} \mathrm{C}$. Before the analysis carried out, samples were diluted using distilled water.

\section{RESULTS AND DISCUSSION}

\section{Preparation of NLCs and NEs}

Different methods are used for the preparation of NLCs and NEs [19, 20]. In the present study, we had adopted a cost-effective, simple and reproducible method for the preparation of nanoemulsions, i.e. High shear homogenization method $[17,18]$.

NLCs were composed of $5(\mathrm{w} / \mathrm{w} \%)$ Naterol GMS and Dermarol DCO ${ }^{\circledR}$ or Dermarol CCT $®$ used in different concentrations and stabilized by $1(\mathrm{w} / \mathrm{w} \%)$ Lecithin as co-surfactant and different ratios of surfactant concentrations Tween 80 and Span 20 (2.5/1, 5/1, $10 / 1,15 / 1) \mathrm{w} / \mathrm{w} \%$, while NEs were composed of $5(\mathrm{w} / \mathrm{w} \%)$ Dermarol DCO® and Dermarol CCT ${ }^{\circledR}$ used in different concentrations and stabilized by $1(\mathrm{w} / \mathrm{w} \%)$ Lecithin as co-surfactant and different ratios of surfactant concentrations Tween 80 and Span $20(2.5 / 1,5 / 1,10 / 1,15 / 1) \mathrm{w} / \mathrm{w} \%$.

\section{Effect of surfactants ratios on particle size}

Fig. [1-12] presents the obtained results for the effect of surfactant ratio on the particle size of NEs and NLCs. firstly fig. 1, 2 demonstrate that the best NEs obtain by using the surfactant concentration ratio 2.5/1 (w/w \%), While fig. 3,4 demonstrate that the best NLC obtained by using the surfactant concentration ratio (5/1), (2.5/1) w/w \%. A similar results were reported by Wulff-Perez et al. [21] who found that at high surfactant concentrations, some surfactant molecules may 
increase the local osmotic pressure, which causes moving of continuous phase between some droplets to them, and this cause depletion of the continuous phase between the drops and the aggregation happened and so the particle size increase. While different results were reported by Chanana et al.[22] Who found that increasing surfactant concentration leads to decrease in particle size of nanoparticles. Fig. [5-12] presents the effect of each surfactant concentration ratio on the particle size of NEs and NLCs.

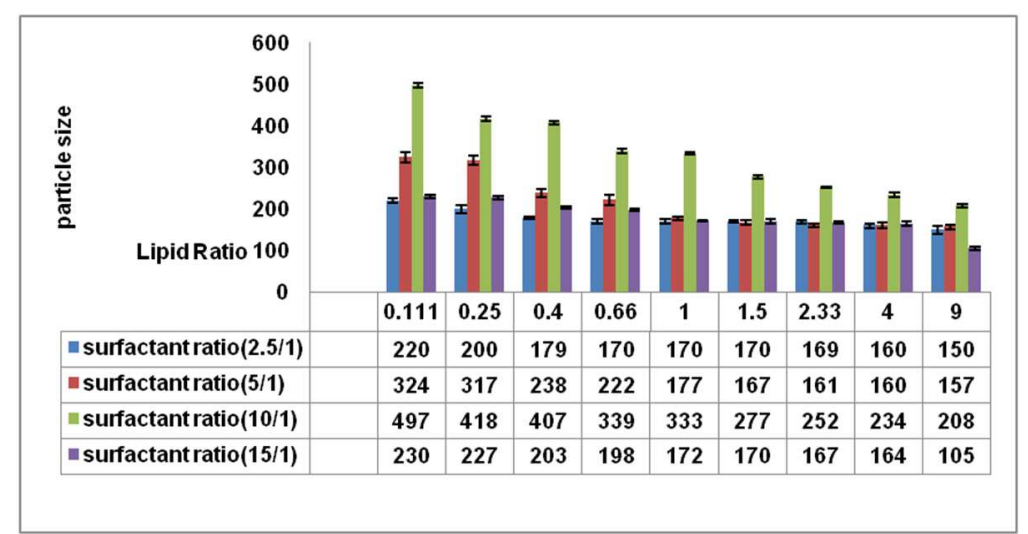

Fig. 1: Effect of surfactant ratio on the particle size of nanoemulsions (NEs) prepared using homogenization speed at $12000 \mathrm{rpm}$ $($ mean $\pm \mathrm{SD}, \mathrm{N}=3$ )

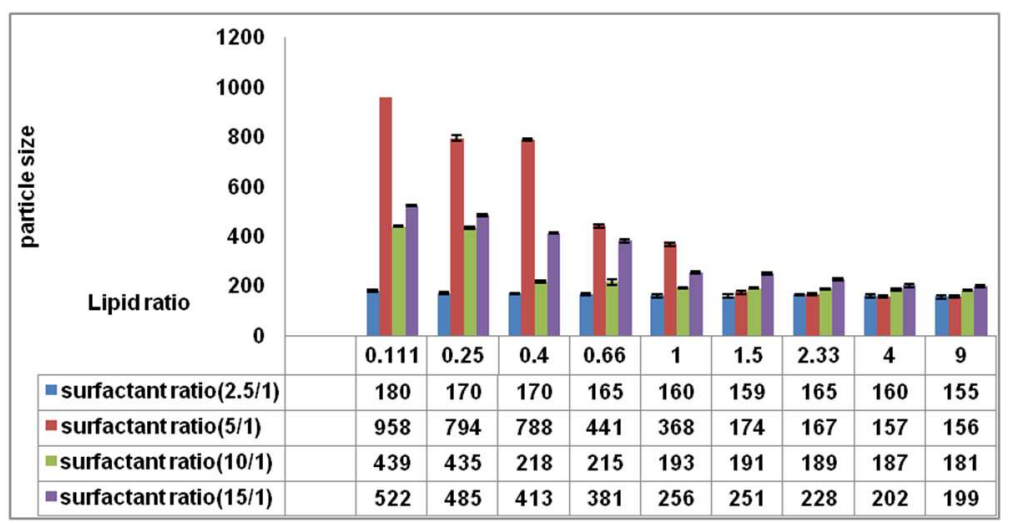

Fig. 2: Effect of surfactant ratio on the particle size of nanoemulsions (NEs) prepared using homogenization speed at $18000 \mathrm{rpm}$ (mean \pm SD, $\mathrm{N}=3$ )

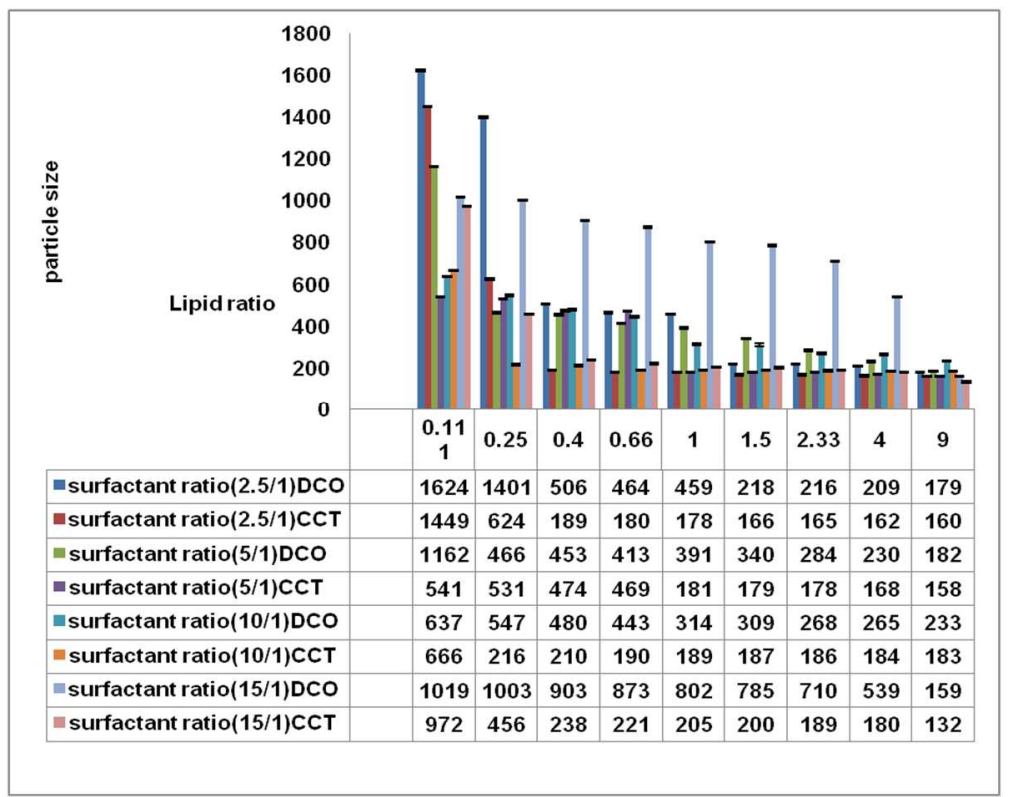

Fig. 3: Effect of surfactant ratio on the particle size of nanostructured lipid carriers (NLCs) prepared using homogenization speed at 12 $000 \mathrm{rpm}($ mean $\pm \mathrm{SD}, \mathrm{N}=3)$ 


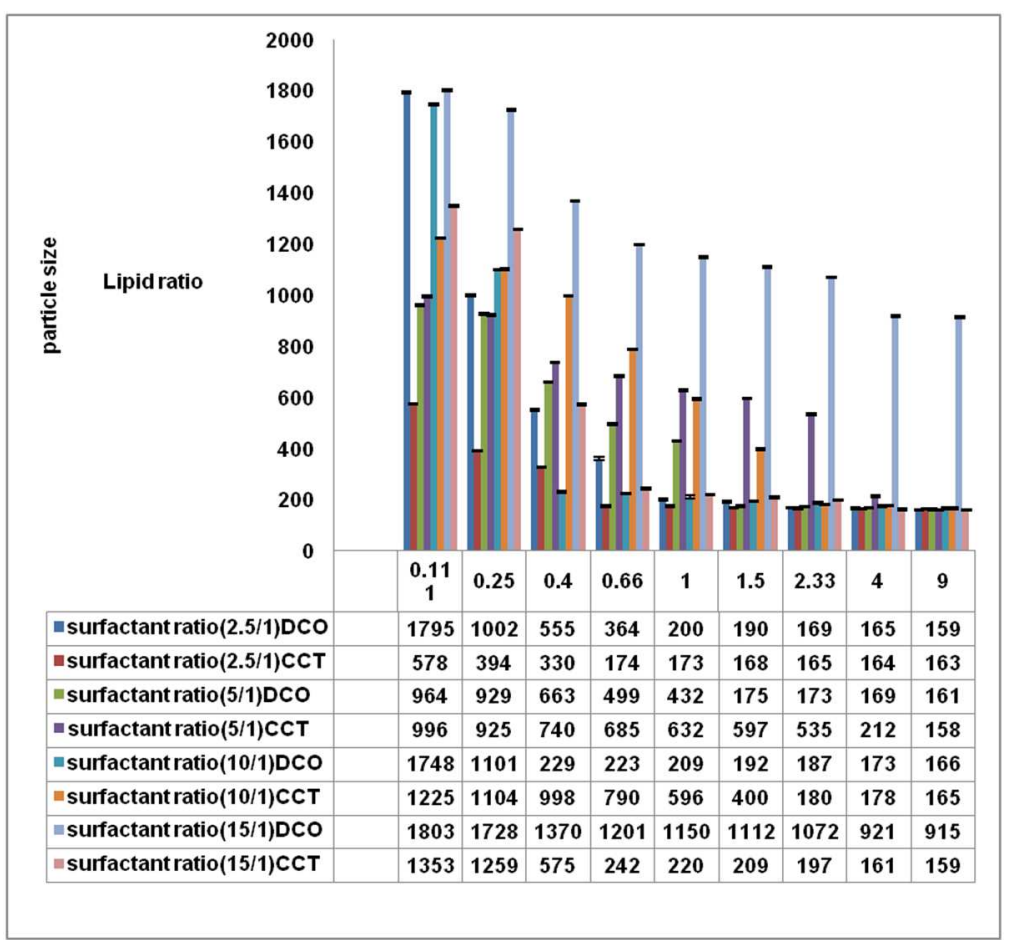

Fig. 4: Effect of surfactant ratio on the particle size of nanostructured lipid carriers (NLCs) prepared using homogenization speed at 18 $000 \mathrm{rpm}($ mean \pm SD, $\mathrm{N}=3$ )

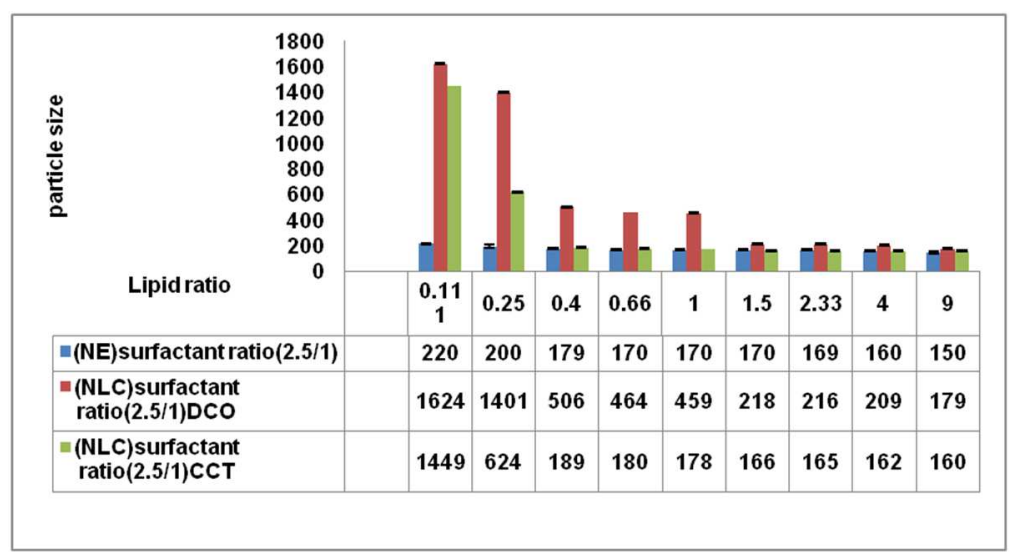

Fig. 5: Effect of surfactant ratio on the particle size of nanostructured lipid carriers (NLCs) and nanoemulsions(NEs) prepared using homogenization speed at $12000 \mathrm{rpm}($ mean $\pm \mathrm{SD}, \mathrm{N}=3$ )

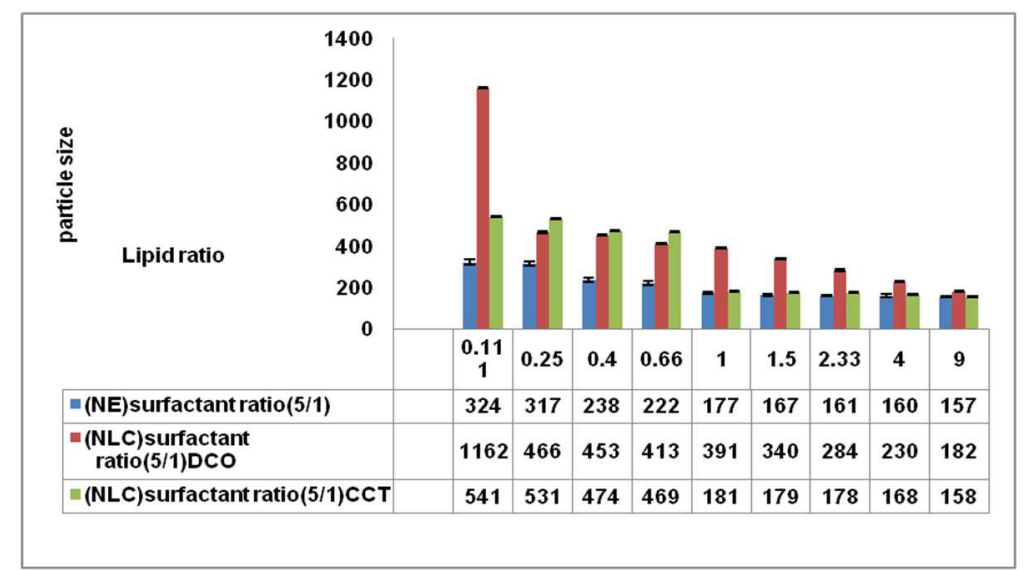

Fig. 6: Effect of surfactant ratio on the particle size of nanostructured lipid carriers (NLCs) and nanoemulsions(NEs) prepared using homogenization speed at $12000 \mathrm{rpm}($ mean $\pm \mathrm{SD}, \mathrm{N}=3)$ 


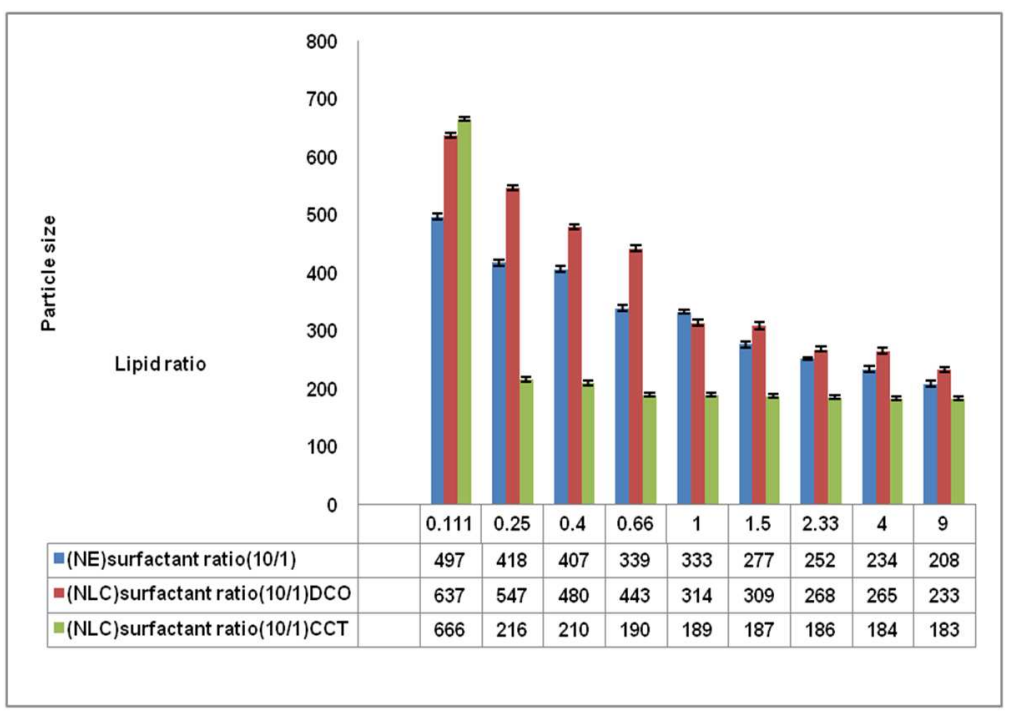

Fig. 7: Effect of surfactant ratio on the particle size of nanostructured lipid carriers (NLCs) and nanoemulsions(NEs) prepared using homogenization speed at $12000 \mathrm{rpm}($ mean $\pm \mathrm{SD}, \mathrm{N}=3)$

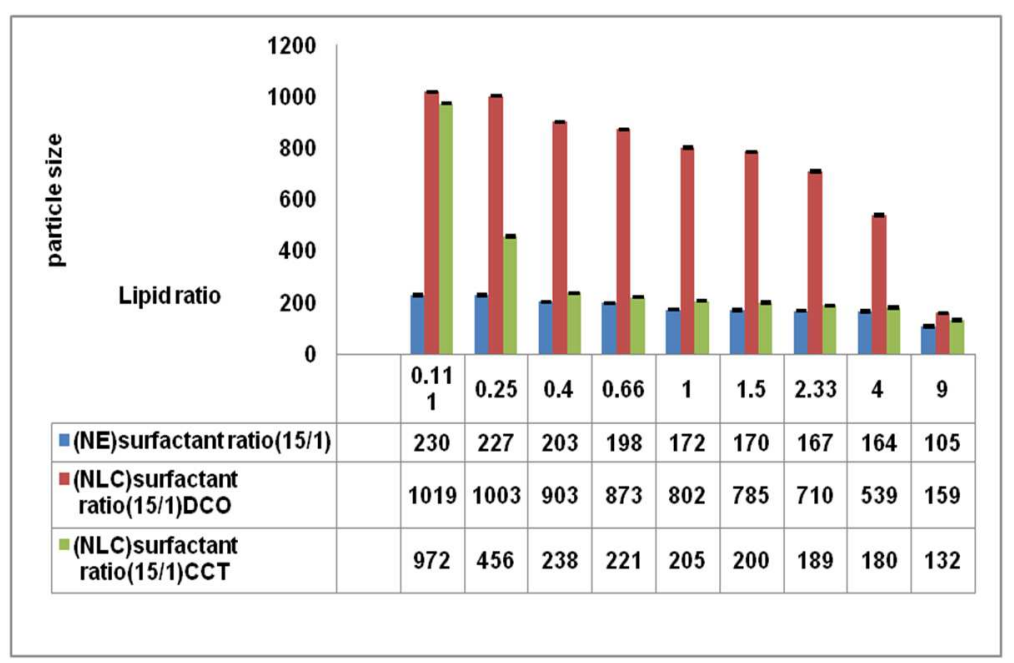

Fig. 8: Effect of certain surfactant ratio on the particle size of nanostructured lipid carriers (NLCs) and nanoemulsions(NEs) prepared using homogenization speed at $12000 \mathrm{rpm}($ mean $\pm \mathrm{SD}, \mathrm{N}=3)$

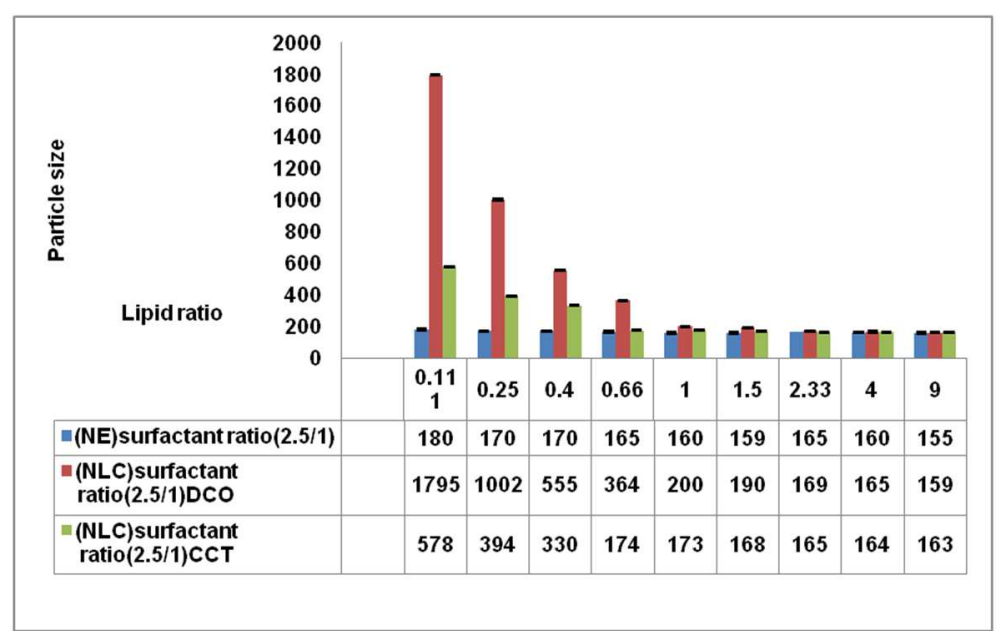

Fig. 9: Effect of certain surfactant ratio on the particle size of nanostructured lipid carriers (NLCs) and nanoemulsions(NEs) prepared using homogenization speed at $18000 \mathrm{rpm}($ mean $\pm \mathrm{SD}, \mathrm{N}=3)$ 


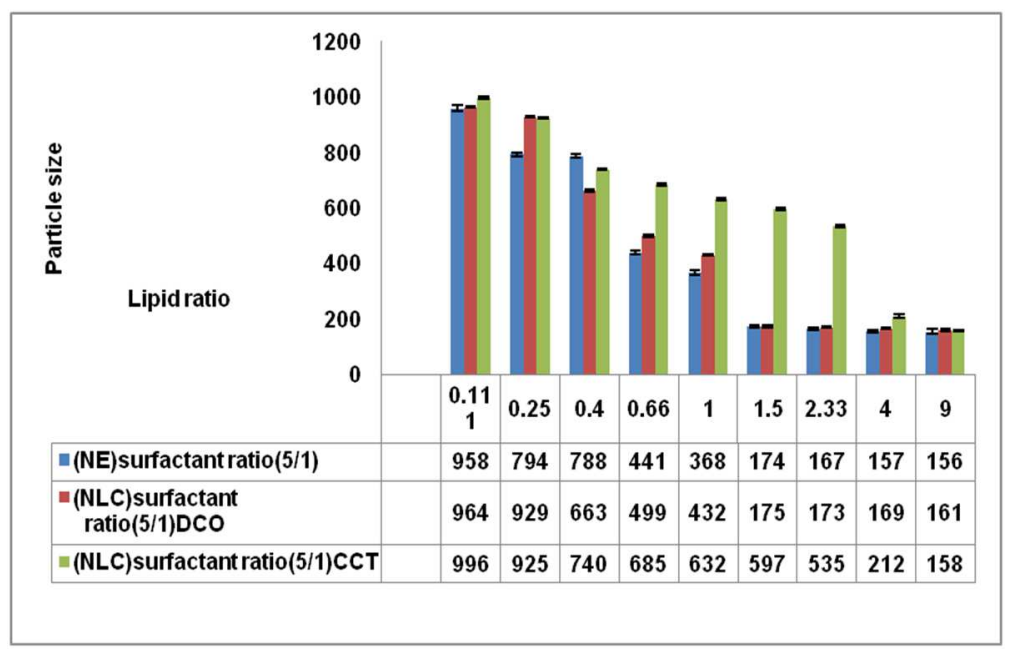

Fig. 10: Effect of certain surfactant ratio on the particle size of nanostructured lipid carriers (NLCs) and nanoemulsions(NEs) prepared using homogenization speed at $18000 \mathrm{rpm}($ mean $\pm \mathrm{SD}, \mathrm{N}=3)$

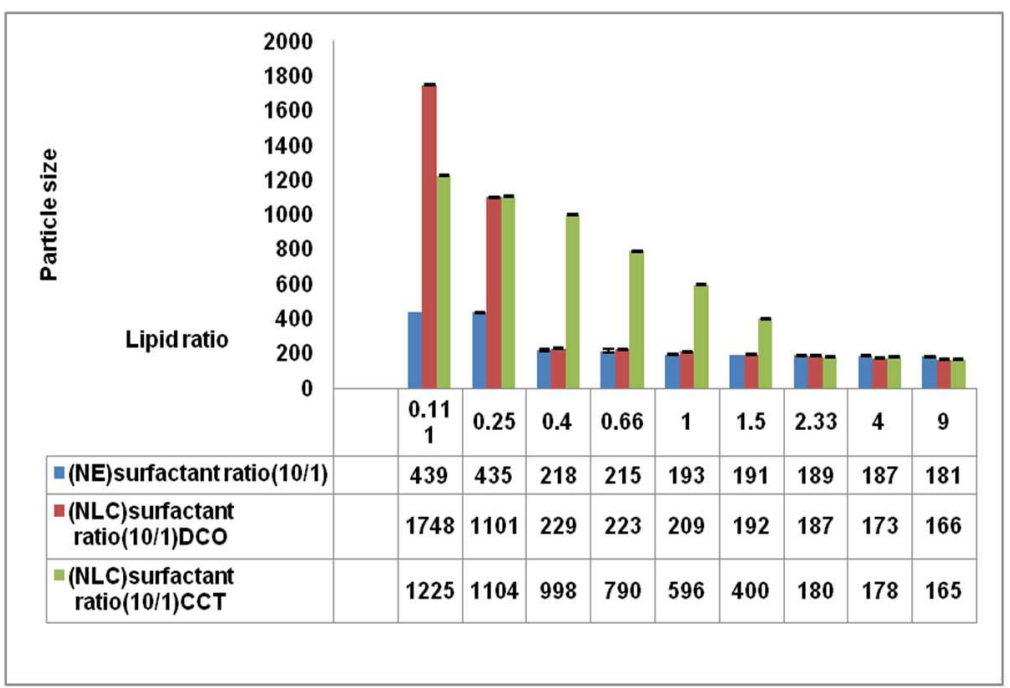

Fig. 11: Effect of surfactant ratio on the particle size of nanostructured lipid carriers (NLCs) and nanoemulsions(NEs) prepared using homogenization speed at $18000 \mathrm{rpm}($ mean $\pm \mathrm{SD}, \mathrm{N}=3$ )

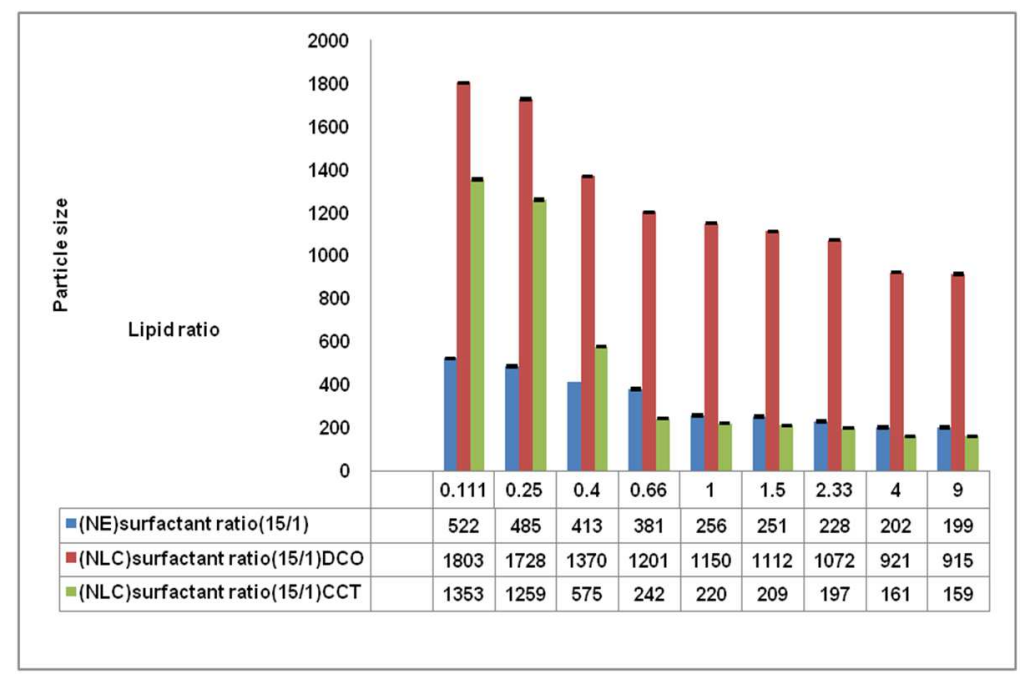

Fig. 12: Effect of surfactant ratio on the particle size of nanostructured lipid carriers (NLCs) and nanoemulsions(NEs) prepared using homogenization speed at $18000 \mathrm{rpm}($ mean $\pm \mathrm{SD}, \mathrm{N}=3)$ 


\section{Effect of lipid type and concentration}

Normally NEs formulate by using two liquid lipids only without solid lipid, While NLCs formulate by using solid lipid and liquid lipid, so we studied the effect of lipid concentrations on NEs particle size and the effect of lipid type and concentration on NLCs particle size. In our study, we used two liquid lipids Dermarol DCO $®$ and Dermarol CCT $®$ in different concentration to prepare NEs and the same liquid lipids each one separately with Naterol GMS as solid lipid to prepare NLCs.

Fig. [13-28] presents the obtained results of the effect of lipid type and concentration on the size of particles. Fig. [13,14, 16-17,19 and 20] demonstrate that NLCs prepared by using liquid lipid dermarol CCT $\circledast$ gave the smallest NLCs particle size, but only figs. 15 and 18 demonstrate that the best NLCs particle size resulted with Dermarol
$\mathrm{DCO} \circledast$ as liquid lipid, the study presents that by increasing the concentration of liquid lipid the particle size of NLCs decrease. A similar results were reported by Puglia, et al. and (Mu and Feng, 2003) who suggested that the addition of liquid lipid to solid lipid tends to promote the formation of small particle population, which may be due to increasing in molecular mobility of the matrix after liquid oil addition [23, 24]. Different results were reported by Soleimanian et al. [25] who suggested that particle size increase by increasing the liquid oil concentrations due to the more disordered crystalline structure inside the nanoparticles. Fig. [21-28] comparisons between NEs and NLCs prepared at different homogenization speed. It was found that the best NEs resulted when we increase Dermarol CCT ${ }^{\circledR}$ concentration and decrease Dermarol DCO ${ }^{\circledR}$ concentration, while the best NLCs obtained when we use Dermarol CCT ${ }^{\circledR}$ as liquid lipid.

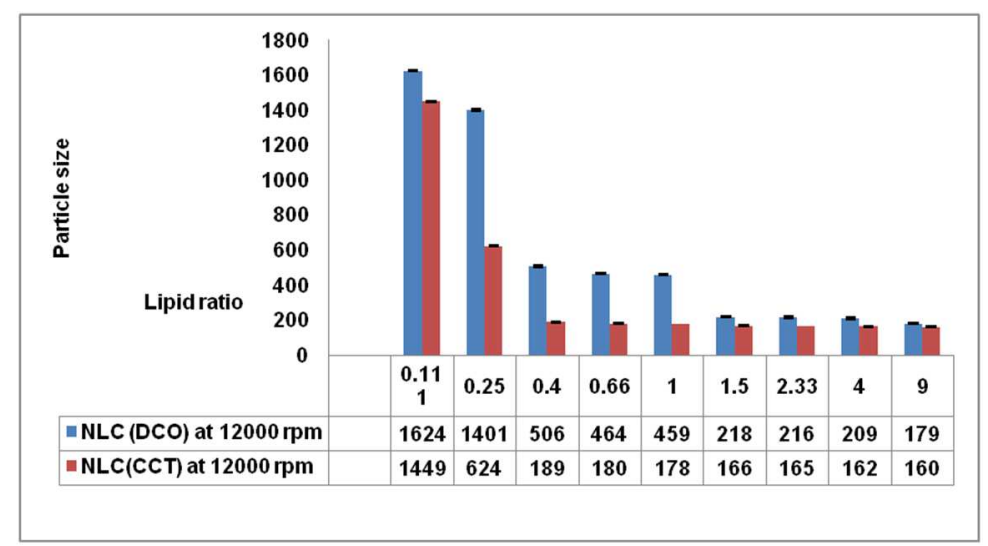

Fig. 13: Effect of lipid type and concentration on the particle size of nanostructured lipid carriers (NLCs) prepared with a surfactant ratio $(2.5 / 1)(m e a n \pm S D, N=3)$

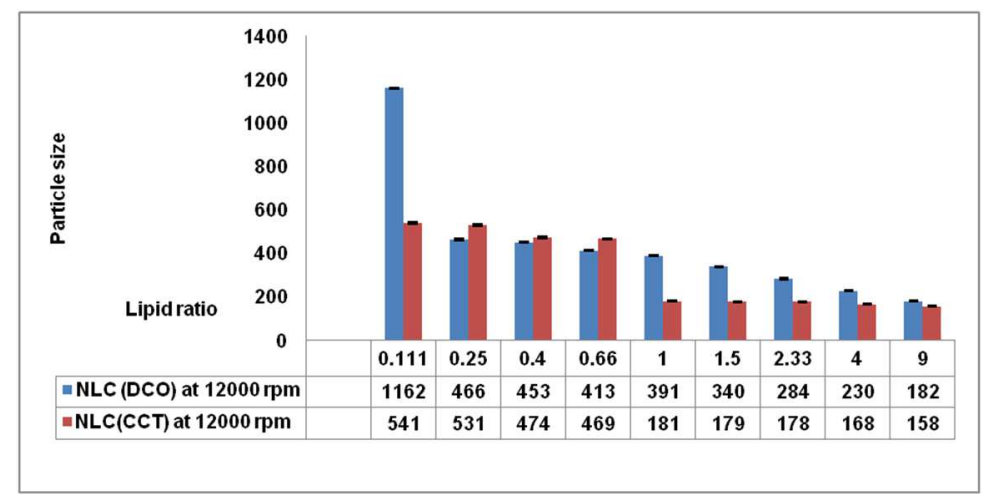

Fig. 14: Effect of lipid type and concentration on the particle size of nanostructured lipid carriers (NLCs) prepared with a surfactant ratio $(5 / 1)($ mean $\pm S D, N=3)$

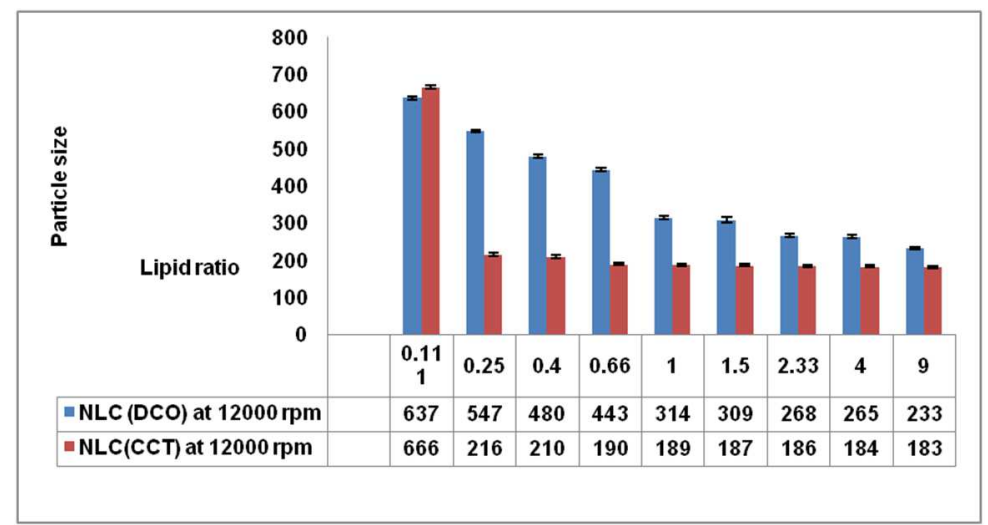

Fig. 15: Effect of lipid type and concentration on the particle size of nanostructured lipid carriers (NLCs) prepared with a surfactant ratio $(10 / 1)($ mean $\pm S D, N=3)$ 


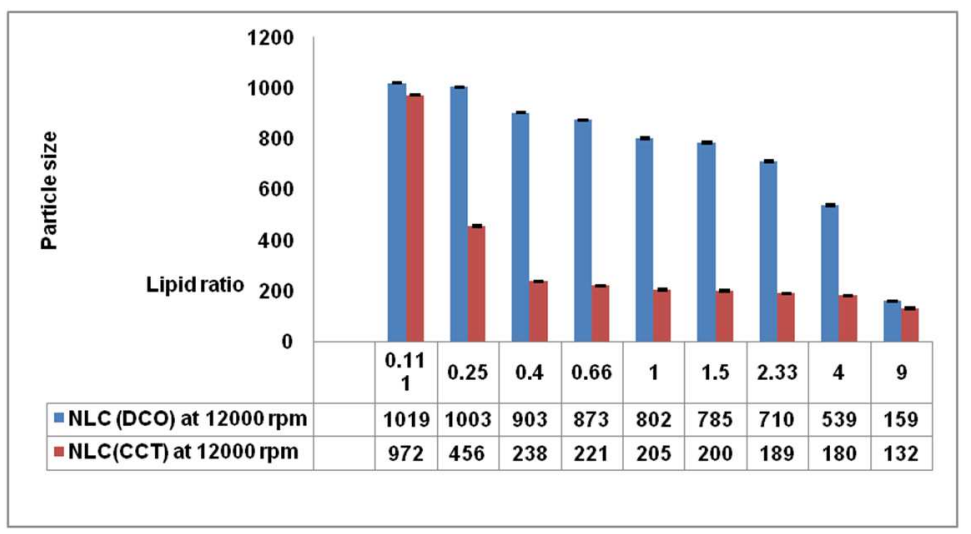

Fig. 16: Effect of lipid type and concentration on the particle size of nanostructured lipid carriers (NLCs) prepared with a surfactant ratio $(15 / 1)(m e a n \pm S D, N=3)$

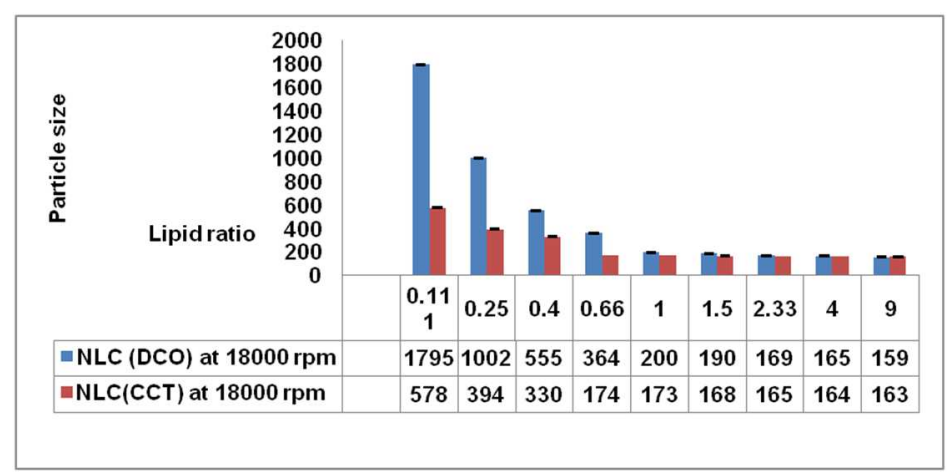

Fig. 17: Effect of lipid type and concentration on the particle size of nanostructured lipid carriers (NLCs) and prepared with a surfactant ratio $(2.5 / 1)($ mean $\pm \mathrm{SD}, \mathrm{N}=3)$

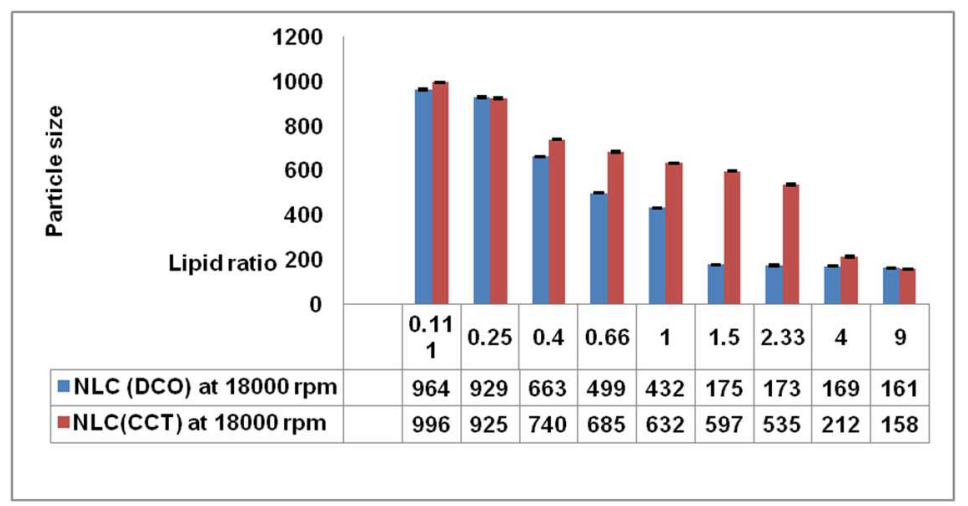

Fig. 18: Effect of lipid type and concentration on the particle size of nanostructured lipid carriers (NLCs) prepared with a surfactant ratio $(5 / 1)($ mean $\pm S D, N=3)$

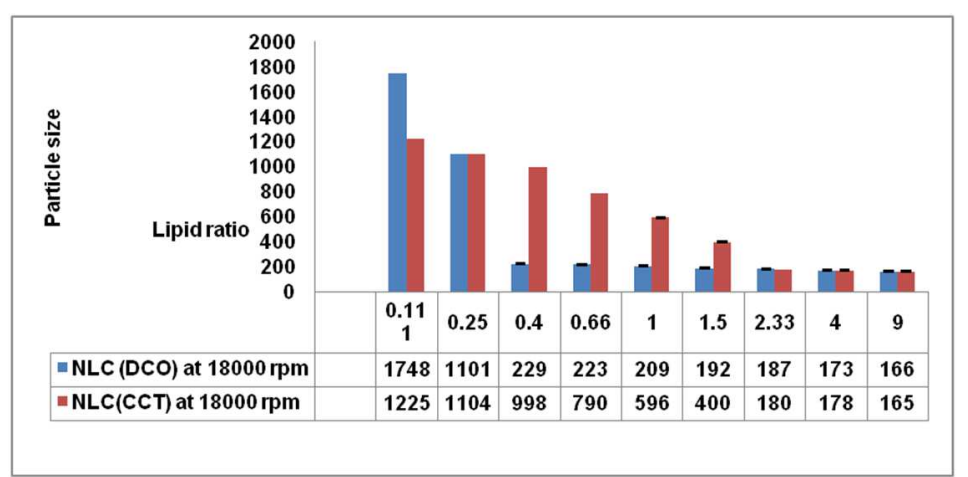

Fig. 19: Effect of lipid type and concentration on the particle size of nanostructured lipid carriers (NLCs) prepared with a surfactant ratio $(10 / 1)(m e a n \pm S D, N=3)$ 


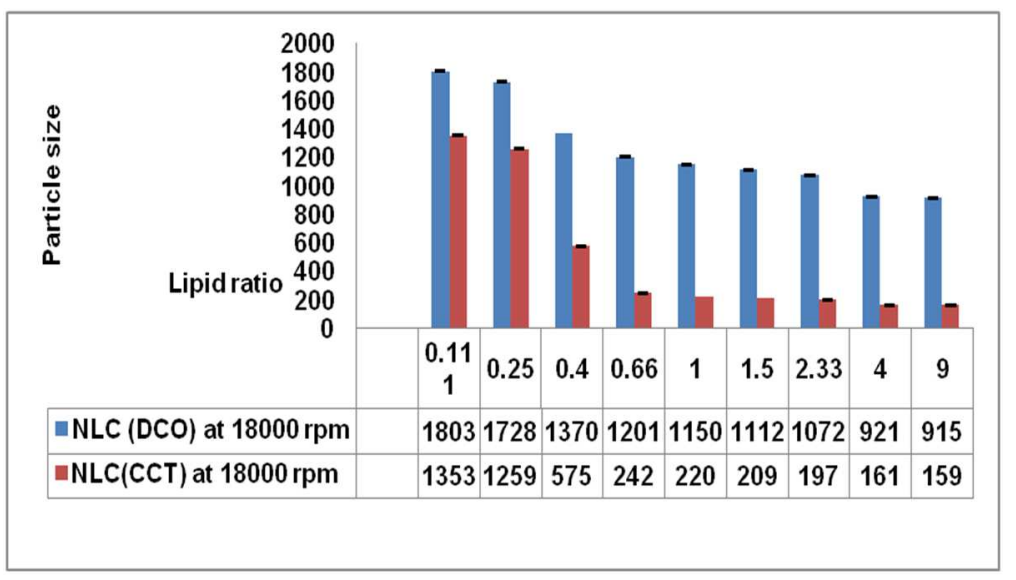

Fig. 20: Effect of lipid type and concentration on the particle size of nanostructured lipid carriers (NLCs) prepared with a surfactant ratio $(15 / 1)(m e a n \pm S D, N=3)$

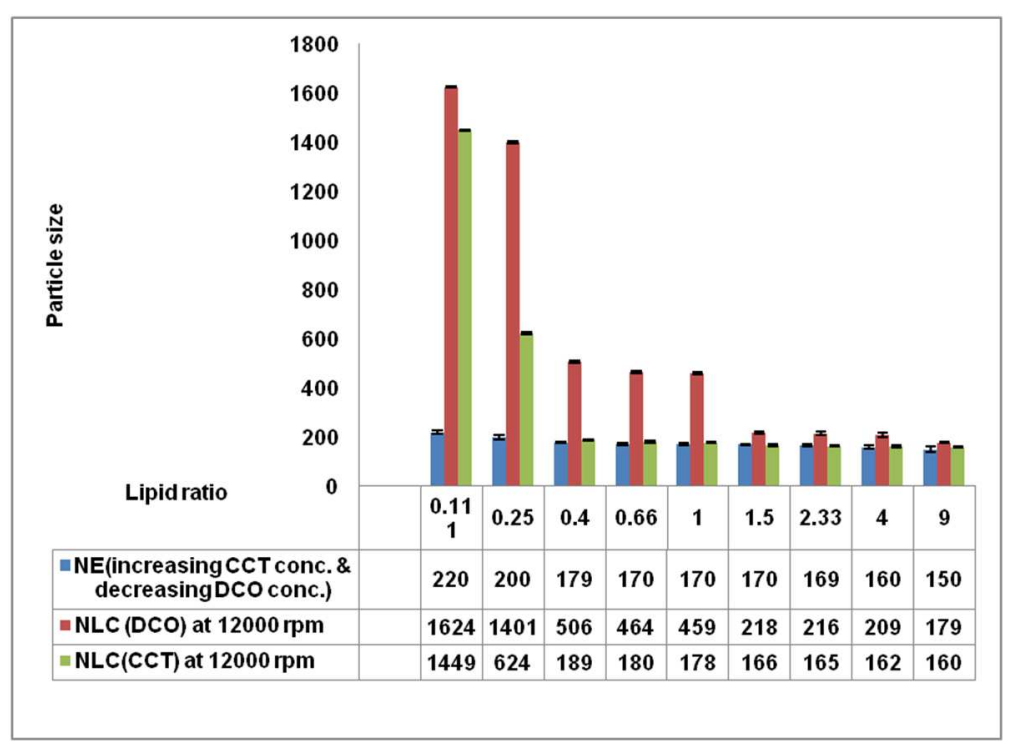

Fig. 21: Effect of lipid type and concentration on the particle size of nanostructured lipid carriers (NLCs) and nanoemulsions(NEs) prepared with a surfactant ratio $(2.5 / 1)($ mean $\pm \mathrm{SD}, \mathrm{N}=3)$

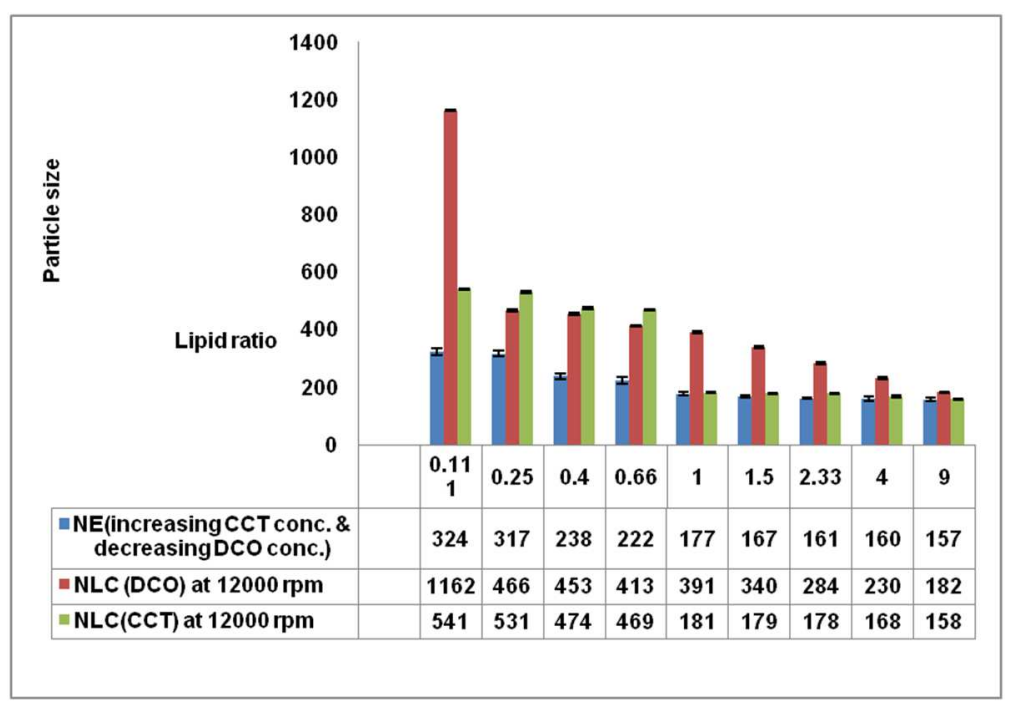

Fig. 22: Effect of lipid type and concentration on the particle size of nanostructured lipid carriers (NLCs) and nanoemulsions(NEs) prepared with a surfactant ratio $(5 / 1)($ mean $\pm \mathrm{SD}, \mathrm{N}=3)$ 


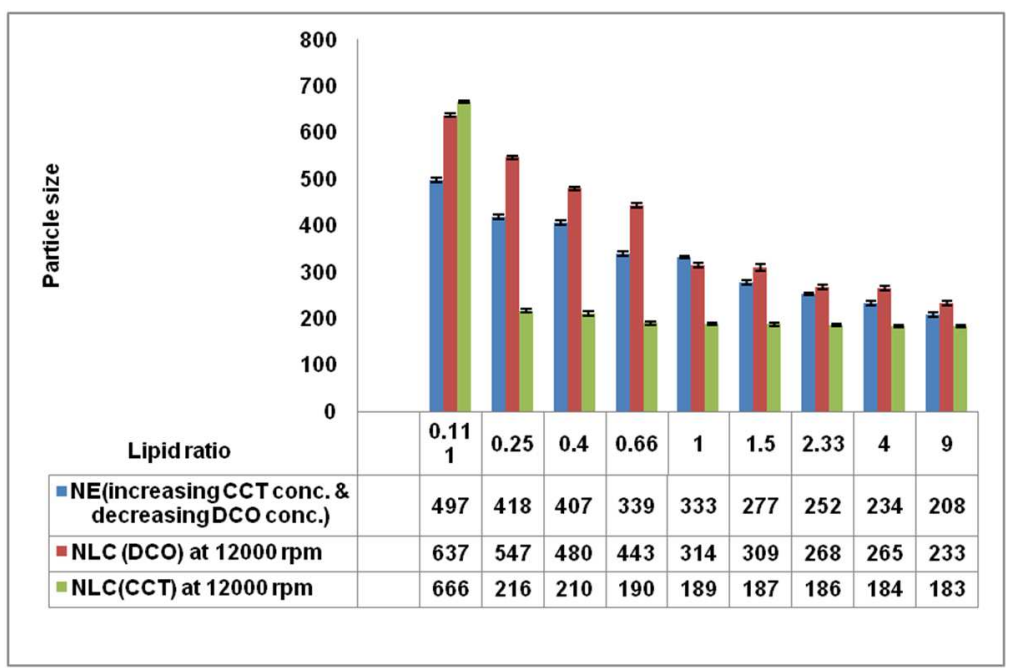

Fig. 23: Effect of lipid type and concentration on the particle size of nanostructured lipid carriers (NLCs) and nanoemulsions(NEs) prepared with a surfactant ratio $(10 / 1)($ mean $\pm S D, N=3)$

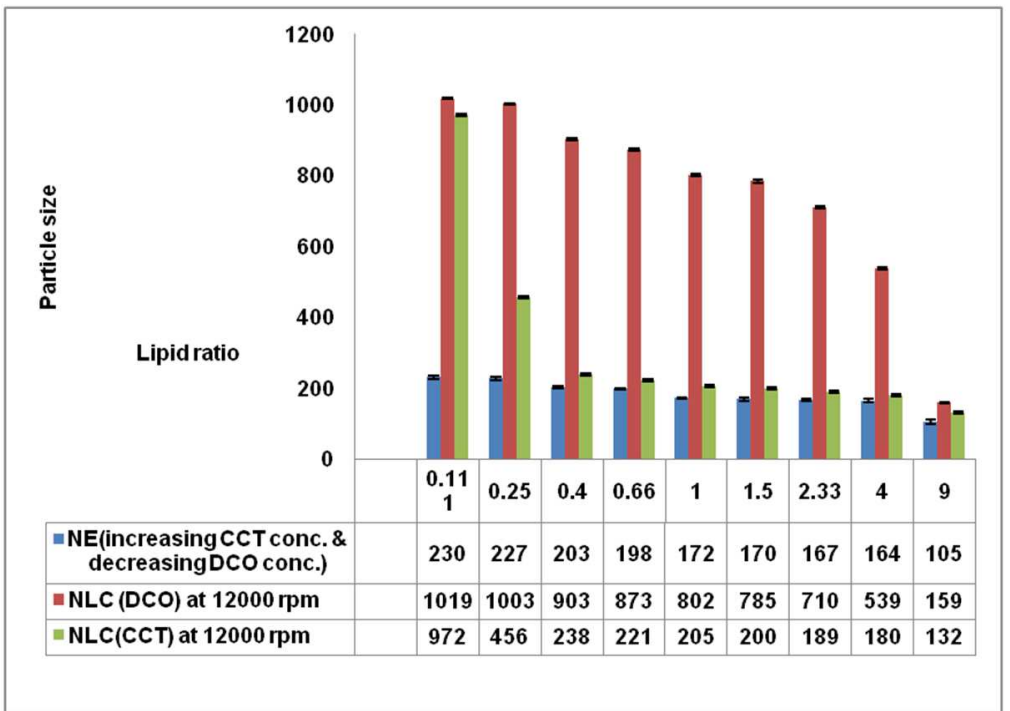

Fig. 24: Effect of lipid type and concentration on the particle size of nanostructured lipid carriers (NLCs) and nanoemulsions(NEs) prepared with a surfactant ratio $(15 / 1)($ mean $\pm S D, N=3)$

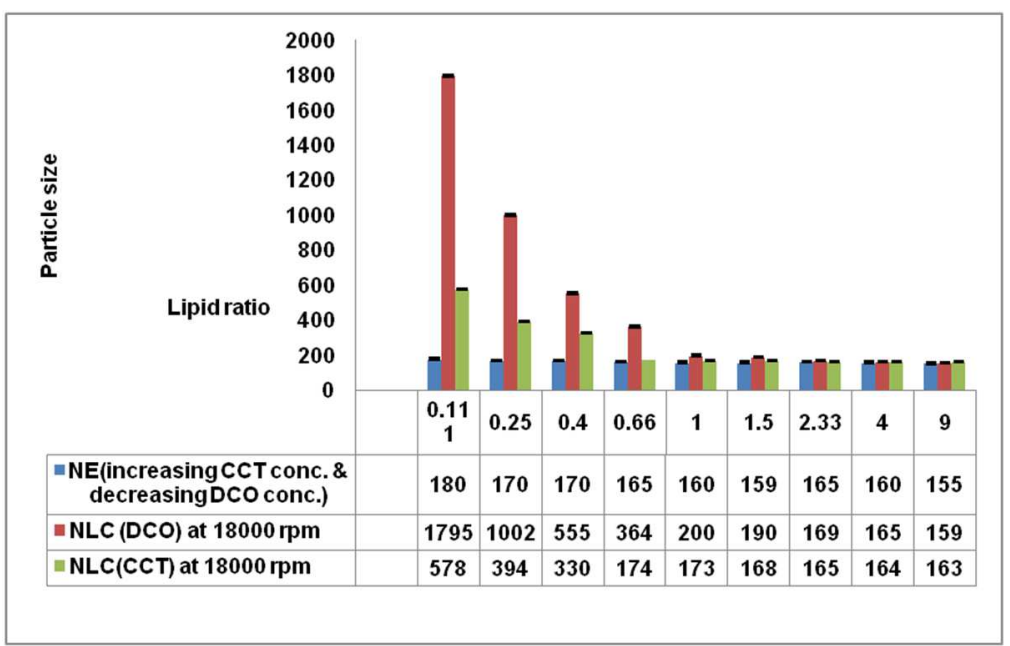

Fig. 25: Effect of lipid type and concentration on the particle size of nanostructured lipid carriers (NLCs) and nanoemulsions(NEs) prepared with a surfactant ratio $(2.5 / 1)($ mean $\pm S D, N=3)$ 


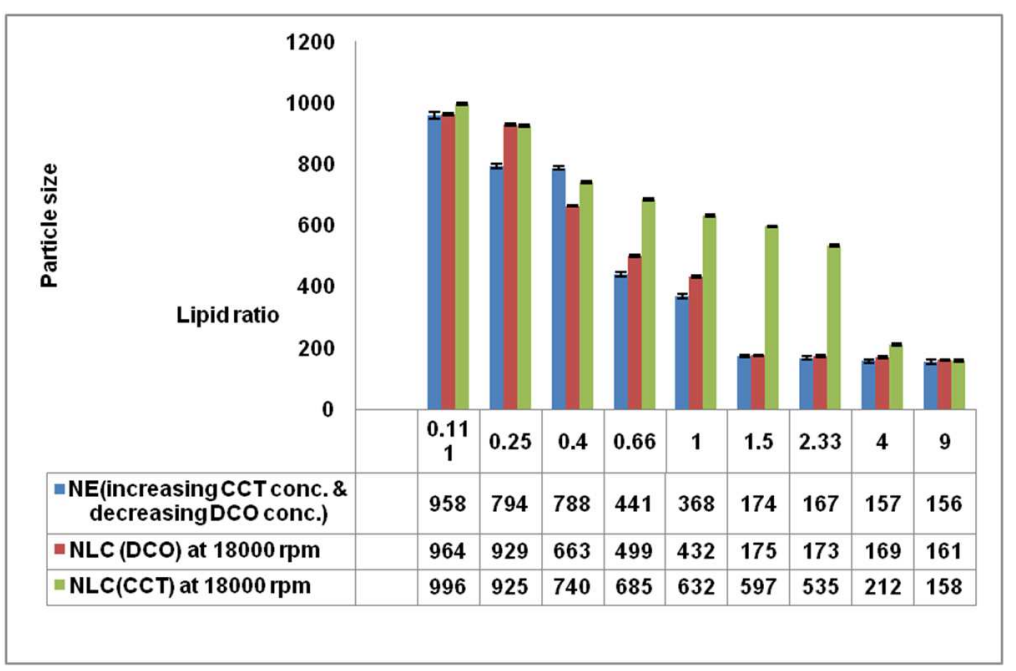

Fig. 26: Effect of lipid type and concentration on the particle size of nanostructured lipid carriers (NLCs) and nanoemulsions(NEs) prepared with a surfactant ratio $(5 / 1)($ mean $\pm \mathrm{SD}, \mathrm{N}=3)$

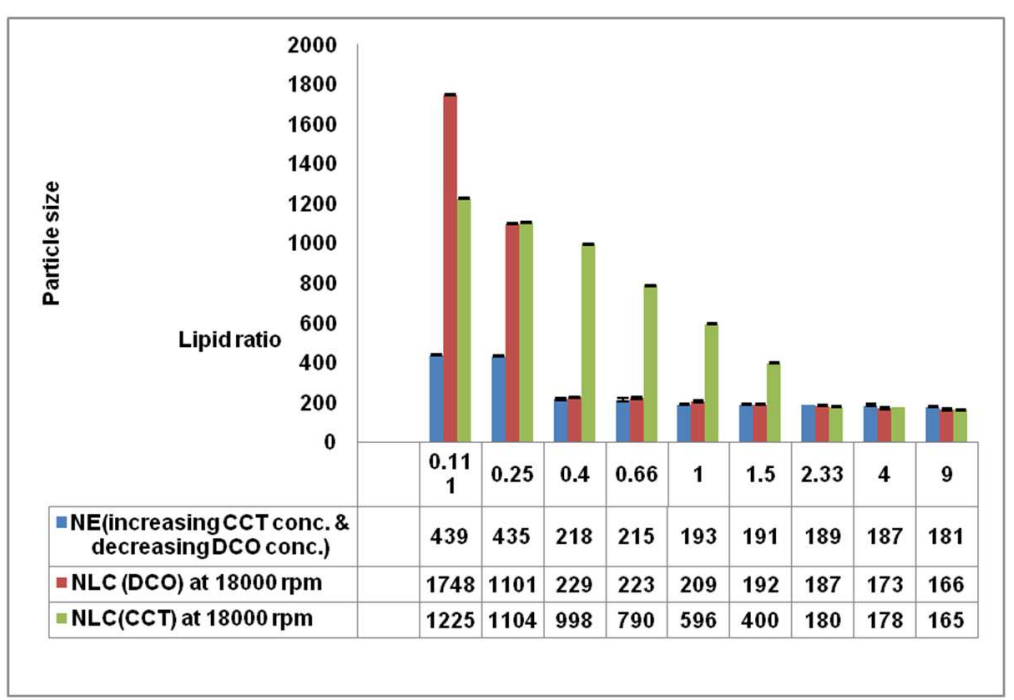

Fig. 27: Effect of lipid type and concentration on the particle size of nanostructured lipid carriers (NLCs) and nanoemulsions(NEs) prepared with a surfactant ratio $(10 / 1)($ mean $\pm S D, N=3)$

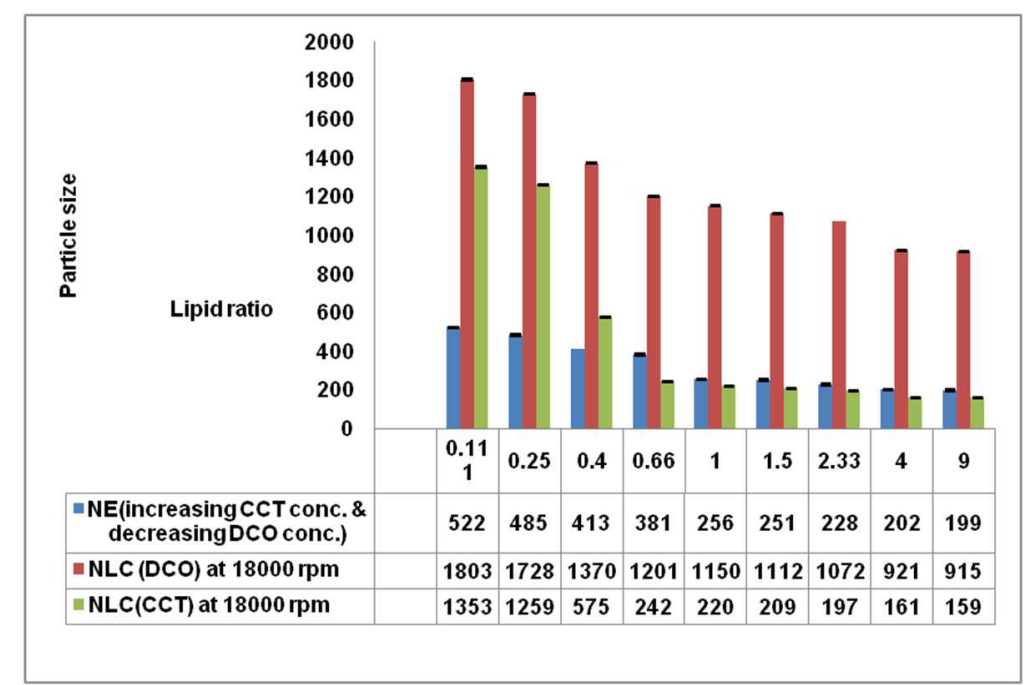

Fig. 28: Effect of lipid type and concentration on the particle size of nanostructured lipid carriers (NLCs) and nanoemulsions(NEs) prepared with a surfactant ratio $(15 / 1)($ mean $\pm S D, N=3)$ 


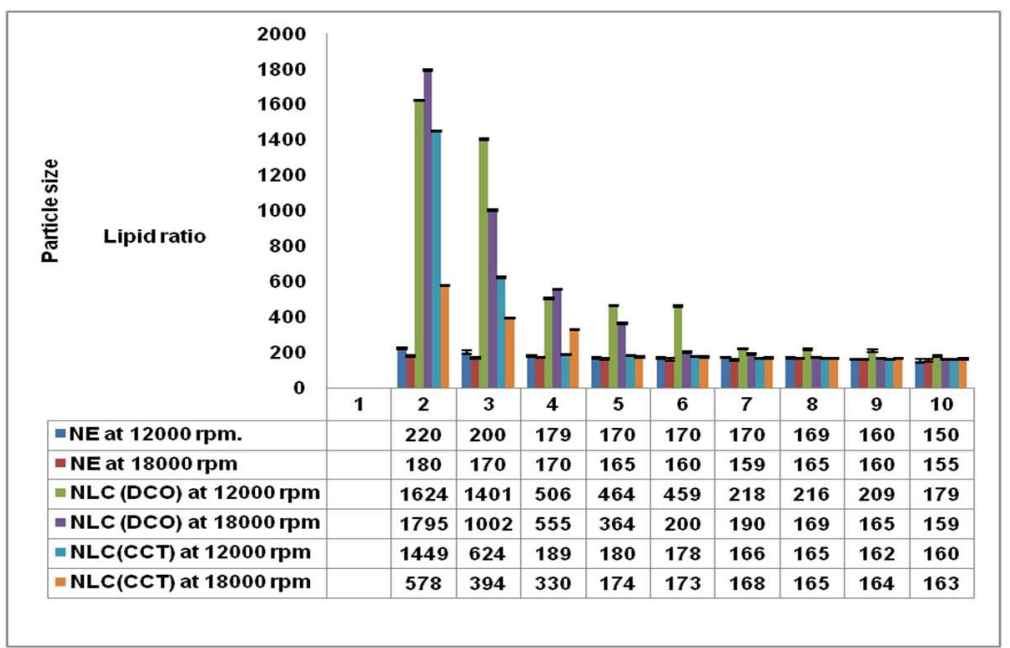

Fig. 29: Effect of homogenization speed on the particle size of nanostructured lipid carriers (NLCs) and nanoemulsions(NEs) prepared with a surfactant ratio $(2.5 / 1)($ mean $\pm \mathrm{SD}, \mathrm{N}=3)$

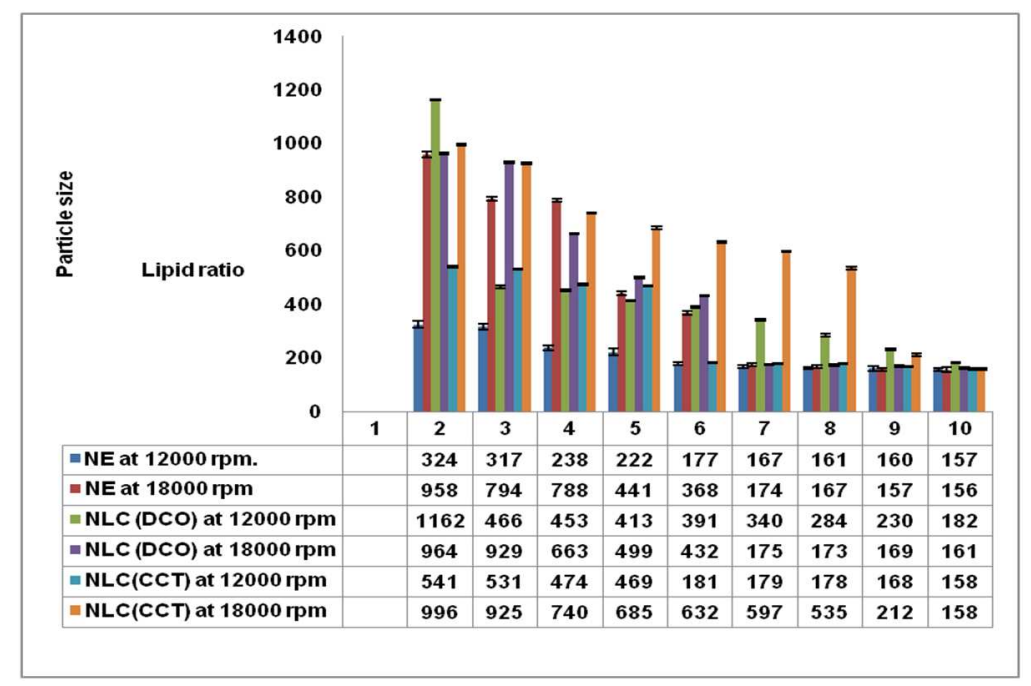

Fig. 30: Effect of homogenization speed on the particle size of nanostructured lipid carriers (NLCs) and nanoemulsions (NEs) prepared with a surfactant ratio (5/1) (mean $\pm \mathrm{SD}, \mathrm{N}=3)$

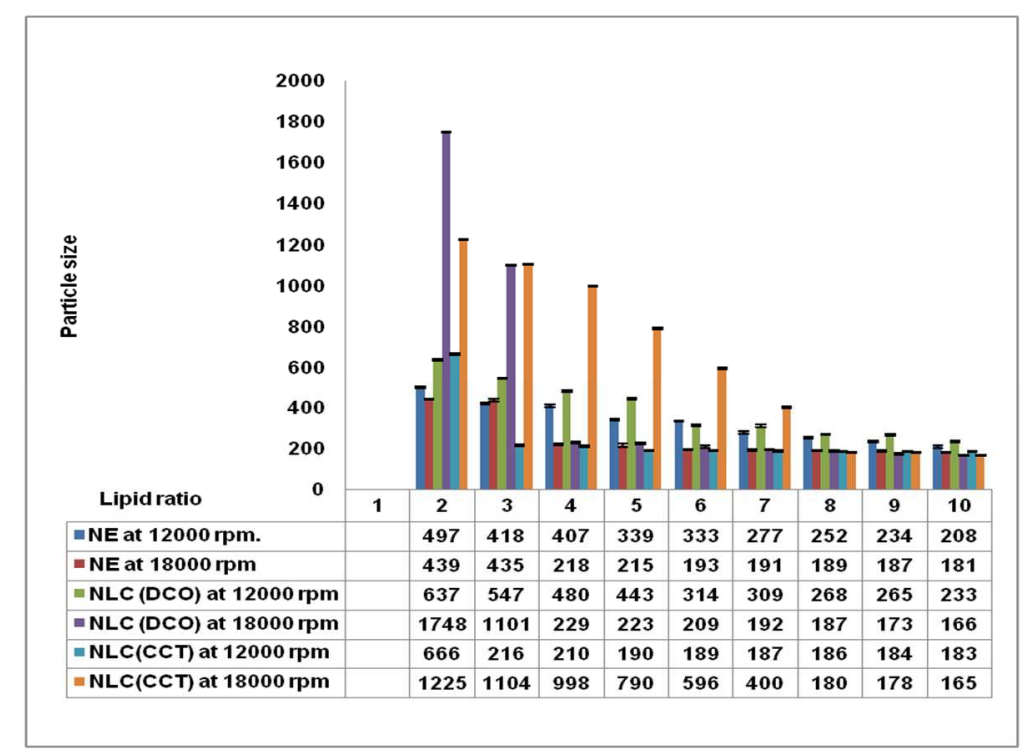

Fig. 31: Effect of homogenization speed on the particle size of nanostructured lipid carriers (NLCs) and nanoemulsions (NEs) prepared with a surfactant ratio $(10 / 1)($ mean $\pm S D, N=3)$ 


\section{Effect of homogenization speed}

Results of the effect of homogenization speed on the particle size of NEs and NLCs are illustrated in fig. [29-32]. This fig. reveal that increasing the homogenization speed from 12000 to $18000 \mathrm{rpm}$. Led to decrease the particle size of NEs and NLCs.

A similar result was obtained by Kovacevic et al. [26] who found that smaller particle size are obtained by increasing the homogenization speed which may be attributable to the increased force of deforming droplets at higher speed results in a decrease of particles. A different result was obtained by Lander et al. [27] who found that smaller particle sizes are acquired by increasing the processing temperatures because of the lowered viscosity of the lipid phase, the increase of the homogenization speed resulted in an increase of the particle size due to particle coalescence, this occurred because of the high kinetic energy of the particles. It was found that the best NEs and NLCs particle size obtained at homogenization speed $18000 \mathrm{rpm}$.

NLCs formulated at surfactant concentration ratio $2.5 / 1(\mathrm{w} / \mathrm{w} \%)$ present that the mean particle size of the resulted formulations when using homogenization speed 12 000rpm ranging from $1623 \mathrm{~nm}$ to 179 $\mathrm{nm}$ while the mean particle size of the resulted formulations when using homogenization speed $18000 \mathrm{rpm}$ ranging from $1795 \mathrm{~nm}$ to $158 \mathrm{~nm}$.

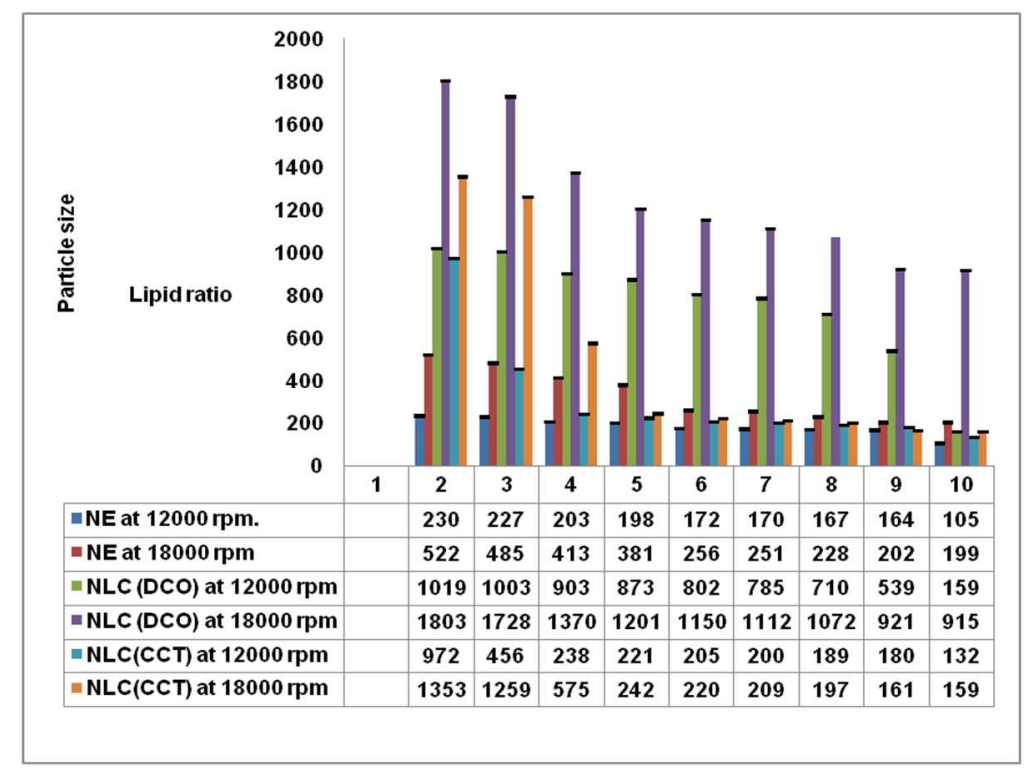

Fig. 32: Effect of homogenization speed on the particle size of nanostructured lipid carriers (NLCs) and nanoemulsions(NEs) prepared with a surfactant ratio $(15 / 1)($ mean $\pm \mathrm{SD}, \mathrm{N}=3)$

\section{CONCLUSION}

Different formulative of factors which influenced the size of particles of NEs and NLCs prepared by high shear homogenization method were successfully studied. The results suggested the importance of controlling the critical formulation and process parameters during formulation such as (type of liquid lipids, homogenization speed, and surfactant concentration ratio) as they greatly affected the particle size of the final prepared nanoparticles. The optimum NLCs resulted when we use Dermarol CCT® as liquid lipid and surfactant ratio $2.5 / 1(\mathrm{w} / \mathrm{w} \%)$ with homogenization speed $18000 \mathrm{rpm}$ or with a surfactant ratio $10 / 1 \mathrm{w} / \mathrm{w}$ $\%$ ) and homogenization speed $12000 \mathrm{rpm}$. While the optimum NEs obtained when we increase Dermarol CCT ${ }^{\circledR}$ concentration and use surfactant ratio 2.5/1(w/w \%) with homogenization speed $18000 \mathrm{rpm}$.

\section{AUTHORS CONTRIBUTIONS}

Author Ahmed R. Gardouh designed the study, responsible of correspondence with journal and aided author Samar H. Faheim in laboratory work. All authors co-operated in writing paper, writing results, data interpretation, and reference management.

\section{CONFLICT OF INTERESTS}

Declared none

\section{REFERENCES}

1. Mehnert W, Mäder K. Solid lipid nanoparticles: production, characterization, and applications. Adv Drug Delivery Rev 2001;47:165-96.

2. Sawant KK, Dodiya SS. Recent advances and patents on solid lipid nanoparticles. Recent Pat Drug Delivery Formulation 2008;2:120-35.

3. Prakash RTU, Thiagaraja P. Nanoemulsions for drug delivery through different routes. Res Biotechnol 2011;2:1-13.
4. Sarangi MK, Padhi S. Solid lipid nanoparticles-a review. J Critical Rev 2016;3:1-8.

5. Mueller RH, Maeder K, Gohla S. Solid lipid nanoparticles (SLN) for controlled drug delivery-a review of the State of the art. Eur J Pharm Biopharm 2000;50:161-77.

6. Yuan H, Wang LL, Du YZ, You J, Hu FQ, Zeng S. Preparation and characteristics of nanostructured lipid carriers for controlreleasing progesterone by melt-emulsification. Colloids Surf B 2007;60:174-9.

7. Teeranachaideekul V, Müller RH, Junyaprasert VB. Encapsulation of ascorbyl palmitate in nanostructured lipid carriers (NLC)-effects of formulation parameters on physicochemical stability. Int J Pharm 2007;340:198-206.

8. Müller R, Petersen R, Hommoss A, Pardeike J. Nanostructured lipid carriers (NLC) in cosmetic dermal products. Adv Drug Delivery Rev 2007;59:522-30.

9. Putranti AR, Primaharinastiti R, Hendradi E. Effectivity and physicochemical stability of nanostructured lipid carrier coenzyme Q10 in a different ratio of lipid cetyl palmitate and alpha tocopheryl acetate as a carrier. Asian J Pharm Clin Res 2017;10:146-52.

10. Duarah S, Pujari K, Duran R, Narayanan V. Nanotechnologybased cosmeceuticals: a review. Int J Appl Pharm 2016;8:1-12.

11. Abdelgawad R, Nasr M, Hamza M, Awad G. Topical and systemic dermal carriers for psoriasis. Int J Curr Pharm Res 2016;8:4-9.

12. Tadros T, Izquierdo P, Esquena J, Solans C. Formation and stability of nano-emulsions. Adv Colloid Interface Sci 2004;108:303-18.

13. Mason T, Graves S, Wilking J, Lin M. Extreme emulsification: formation and structure of nanoemulsions. Condens Matter Phys 2006;9:1-8.

14. Graves S, Meleson K, Wilking J, Lin M, Mason T. Structure of concentrated nanoemulsions. J Chem Phys 2005;122:703-6.

15. Jafari SM, He Y, Bhandari B. Optimization of nano-emulsions production by microfluidization. Eur Food Res Technol 2007;225:733-41. 
16. Qian C, McClements DJ. Formation of nanoemulsions stabilized by model food-grade emulsifiers using high-pressure homogenization: factors affecting particle size. Food Hydrocolloids 2011;25:1000-8.

17. Uner M. Preparation, characterization and physicochemical properties of solid lipid nanoparticles (SLN) and nanostructured lipid carriers (NLC): their benefits as colloidal drug carrier systems. Die Pharmazie 2006;61:375-86.

18. Suraweera R, Pasansi H, Sakeena M. Assessing the characterizations of ketoprofen loaded and unloaded virgin coconut oil based creamy nanoemulsion. Asian J Pharm Clin Res 2015;8:275-9.

19. Meleson K, Graves S, Mason TG. Formation of concentrated nanoemulsions by extreme shear. Soft Mater 2004;2:109-23.

20. Landfester K, Tiarks F, Hentze HP, Antonietti M. Polyaddition in miniemulsions: a new route to polymer dispersions. Macromol Adv Chem Phys 2000;201:1-5.

21. Wulff-Perez M, Torcello-Gomez A, Galvez-Ruiz M, MartínRodríguez A. Stability of emulsions for parenteral feeding: preparation and characterization of $0 / \mathrm{W}$ nanoemulsions with natural oils and pluronic F68 as a surfactant. Food Hydrocolloids 2009;23:1096-102.
22. Chanana GD, Sheth BB. Particle size reduction of emulsions by formulation design-ii: effect of oil and surfactant concentration. PDA J Pharm Sci Technol 1995;49:71-6.

23. Puglia C, Blasi P, Rizza L, Schoubben A, Bonina F, Rossi C, et al. Lipid nanoparticles for prolonged topical delivery: an in vitro and in vivo investigation. Int J Pharm 2008;357:295304.

24. $\mathrm{Mu} \mathrm{L}$, Feng S. A novel controlled release formulation for the anticancer drug paclitaxel (Taxolß): PLGA nanoparticles containing vitamin E. J Controlled Release 2003;86:33-48.

25. Soleimanian Y, Goli SAH, Varshosaz J, Sahafi SM. Formulation and characterization of novel nanostructured lipid carriers made from beeswax, propolis wax and pomegranate seed oil. Food Chem 2018;244:83-92.

26. Kovacevic A, Savic S, Vuleta G, Müller R, Keck C. Polyhydroxy surfactants for the formulation of lipid nanoparticles (SLN and NLC): effects on size, physical stability, and particle matrix structure. Int J Pharm 2011;406:163-72.

27. Lander R, Manger W, Scouloudis M, Ku A, Davis C, Lee A. Gaulin homogenization: a mechanistic study. Biotechnol Prog 2000;16:80-5. 